\title{
ORGANIZAÇÕES DOCENTES NA REFORMA DO ENSINO MÉDIO: ANÁLISE DO POSICIONAMENTO DA ANFOPE E DA CNTE
}

\author{
TEACHING ORGANIZATIONS IN THE REFORM OF HIGHSCHOOL: ANALYSIS OF THE POSITIONING OF ANFOPE AND CNTE
}

ORGANIZACIONES DOCENTES EN LA REFORMA DE LA ESCUELA SECUNDARIA: ANÁLISIS DEL POSICIONAMIENTO DE LA ANFOPE Y CNTE

\author{
BARBOSA, Carlos Soares ${ }^{1}$
}

\begin{abstract}
RESUMO
O artigo visa a analisar o posicionamento político da Associação Nacional pela Formação dos Profissionais da Educação (ANFOPE) e da Confederação Nacional dos Trabalhadores em Educação (CNTE) quanto à reforma do Ensino Médio e à Base Nacional Comum Curricular. É resultado da pesquisa documental, com base nos documentos produzidos pelas referidas organizações entre os anos de 2016 e 2018. Após contextualizar o golpe de 2016 e analisar a reforma educacional no conjunto das demais reformas, o estudo ressalta a importância das organizaç̃es coletivas no atual contexto de ataque a democracia e aos direitos garantidos, entre eles, o direito das camadas populares à educação socialmente qualificada.
\end{abstract}

Palavras-chave: Ensino Médio. Reforma. ANFOPE. CNTE.

\section{ABSTRACT}

The article aims to analyze the political position of the ANFOPE and the CNTE regarding the reform of High School and the National Curricular Common Base. It is the result of documentary research, based on the documents produced by these organizations between 2016 and 2018. After contextualizing the 2016 coup and analyzing educational reform in all other reforms, the study highlights the importance of collective organizations in the current context of attacking democracy and guaranteed rights, among them, the right of the popular classes to socially qualified education.

Keywords: Highschool. Reform. ANFOPE. CNTE.

\section{RESUMEN}

El artículo visa analizar el posicionamiento político de la Asociación Nacional por la Formación de los Profesionales de la Educación (ANFOPE) y de la Confederación Nacional de los Trabajadores en Educación (CNTE) en cuanto a la reforma de la Enseñanza Media y a la Base Nacional Común Curricular. Es resultado de la investigación documental, con base en los documentos producidos por las referidas organizaciones entre los años 2016 y 2018. Después de contextualizar el golpe del 2016 y analizar la reforma educacional en el conjunto de las demás reformas, el estudio resalta la importancia de las organizaciones colectivas en el actual contexto de ataque a la democracia y a los derechos garantizados, entre ellos, el derecho de las camadas populares a la educación socialmente cualificada.

Palabras clave: Escuela secundaria. Reforma. ANFOPE. CNTE.

\footnotetext{
${ }^{1}$ Universidade do Estado do Rio de Janeiro - UERJ - Rio de Janeiro - Rio de Janeiro - Brasil.
} 


\section{INTRODUÇÃO}

A atual reforma do Ensino Médio, exarada inicialmente por meio da Medida Provisória $\mathrm{n}^{\circ}$ $746 / 2016$ e transformada na Lei $n^{0} 13.415 / 2017$, tem mobilizado divergentes posicionamentos políticos e colocado em cena diferentes atores sociais. Como toda política, vem se constituindo em um campo de disputa cujas forças são representadas, de um lado, pelo governo e seus apoiadores -classe empresarial e organizações como o Banco Mundial, o Movimento Todos pela Educação, Instituto Ayrton Senna, Instituto Unibanco, Fundação Lemann -; e do outro, estudantes e movimentos estudantis, sindicatos de professores e associações científicas, a exemplo da Confederação Nacional dos Trabalhadores em Educação (CNTE), a Associação Nacional de Pós-Graduação e Pesquisa em Educação (ANPED) e a Associação Nacional pela Formação dos Profissionais da Educação (ANFOPE), por meio da participação em audiências públicas, debates, seminários e congressos em todo país, assim como da elaboração de documentos, moções e assinaturas conjuntas.

Em síntese, o debate sobre o Ensino Médio, no Brasil e em demais países, assenta-se em torno da sua identidade, finalidades e contribuição social, principalmente após a perda do seu caráter tradicionalmente elitista, em decorrência da progressiva democratização da educação pública nos últimos anos e a ampliação do acesso a este nível de ensino às pessoas de novos setores sociais. $\mathrm{A}$ tensão reside entre a perspectiva democratizante, que defende o direito a uma formação geral para todos os jovens brasileiros, e a posição seletiva, que defende a segmentação dos percursos escolares, sobretudo, por ser o Ensino Médio a etapa da escolarização que imediata e mediatamente se relaciona com a transição para o mundo do trabalho para os jovens das camadas mais pauperizadas da classe trabalhadora. Essa tensão se materializa nos "movimentos constantes de reforma na sua estrutura, passando de uma organização única a uma organização com orientações diversas e vice-versa, e as demandas constantes para inclusão e/ou exclusão de novos conteúdos no currículo" (KRAWCKZYC, 2014, p. 79). Disputa esta que se faz presente na recente reforma.

Os argumentos utilizados pelo governo Temer e seus apoiadores para justificar a necessidade da reforma são de que o vigente Ensino Médio é extenso, superficial e fragmentado; não despertando o interesse dos jovens nem favorecendo a aprendizagem e o desenvolvimento das competências necessárias para a vida social do novo milênio, cujo resultado é o baixo desempenho dos estudantes em Língua Portuguesa e Matemática no Sistema de Avaliação da Educação Básica (SAEB) e no Programa Internacional de Avaliação de Alunos (PISA). Limitando o problema da educação brasileira as questões curriculares, a solução apresentada pelo governo e seus apoiadores para reverter esse quadro consiste em seguir os passos dos países que obtiveram a melhora da qualidade de seus sistemas educacionais após abrir espaço para a diversificação de ofertas e escolhas por parte dos alunos, havendo na matriz curricular uma parte composta por disciplinas obrigatórias e optativas, como se as condições estruturais das escolas públicas brasileiras fossem semelhantes à de países como Espanha, Canadá e Finlândia.

A fim de garantir a denominada flexibilização e a suposta possibilidade de escolha aos estudantes, a nova organização curricular passa a ser constituída por uma Base Nacional Comum Curricular (BNCC) e por itinerários formativos, a saber: Linguagens e suas Tecnologias; Matemática e suas 
Tecnologias; Ciências da Natureza e suas Tecnologias; Ciências Humanas e Sociais Aplicadas; Formação Técnica e Profissional.

A proposta de coexistência de uma base nacional comum curricular e de uma parte diversificada se faz presente desde a Constituição de 1988, quando o Artigo 210 determina que sejam "fixados conteúdos mínimos para o ensino fundamental, de maneira a assegurar formação básica comum e respeito aos valores culturais e artísticos, nacionais e regionais" (BRASIL, 1988). É reafirmado no Artigo 26 da Lei de Diretrizes e Bases (LDB) (BRASIL, 1996) e, posteriormente, no vigente Plano Nacional de educação (PNE), Lei n 13.005/2014 (BRASIL, 2014).

Os debates sobre a base iniciaram em 2013 na Comissão Especial da Câmara Federal para o combate e substituição do Projeto de Lei (PL) 6.840/2013, apresentado pelo deputado Reginaldo Lopes (PT-MG). Em seguida as discussões ganharam espaço no Fórum Nacional da Educação (FNE). Contudo, a forma impositiva do governo em promover a reforma por meio de Medida Provisória (MP), desconsiderando o acúmulo das reflexões realizadas até então, demonstra que o respeito à democracia, ao diálogo e a diferença de pensamento não são é perfil do bloco histórico instituído após o golpe parlamentar, jurídico e midiático que se consolidou com o impeachment da presidente Dilma Roussef, em agosto de 2016. As mudanças efetuadas na composição do MEC e no Conselho Nacional de Educação (CNE), bem como a dissolução do FNE já no início do governo Temer sinalizam o objetivo de cercear o debate público e silenciar as vozes discordantes de seu projeto educacional.

Em síntese, a última versão da BNCC-Ensino Médio, aprovada pelo CNE em dezembro de 2018, define o conjunto de aprendizagens essenciais que todos os alunos devem desenvolver ao longo dessa etapa da escolaridade. Com carga horária máxima de 1800 horas, a Base passa a ser organizada não mais em disciplinas isoladas, mas em quatro áreas do conhecimento: Linguagens e suas Tecnologias; Matemática e suas Tecnologias; Ciências da Natureza e suas Tecnologias e Ciências Humanas e Sociais Aplicadas. No entanto, apenas Língua Portuguesa e Matemática passaram a ser disciplinas obrigatórias nos três anos do Ensino Médio, podendo as demais ser tratadas em um ano ou dois, dependendo da organização do currículo definido por cada rede de ensino.

A nova organização curricular focaliza o desenvolvimento de competências, seguindo o enfoque adotado pela Unesco e pelas avaliações internacionais - Pisa. No documento da BNCC, competência é definida como "a mobilização de conhecimentos (conceitos e procedimentos), habilidades (práticas, cognitivas e socioemocionais), atitudes e valores para resolver demandas complexas da vida cotidiana, do pleno exercício da cidadania e do mundo do trabalho" (BRASIL, 2017, p.8). Desse modo, com o golpe de 2016, retoma-se não só a ortodoxia neoliberal como também o projeto educacional fundamentado na Pedagogia das Competências e Habilidades, implementado no governo de Fernando Henrique Cardoso. Daí o apoio do Partido Social Democrático Brasileiro (PSDB) ao golpe e o retorno ao MEC das mesmas pessoas que ocuparam postos estratégicos nos dois mandatos do governo tucano, a exemplo de Maria Helena Guimarães de Castro, que no governo Temer ocupou a função de secretária geral no referido ministério e no governo FHC ocupou a presidência do Instituto Nacional de Estudos e Pesquisas Educacionais (INEP), além de dirigir secretarias nos governos paulistas de José Serra e de Geraldo Alkmin. 
Muitos aspectos da Lei $n^{0}$ 13.415/2017 mobilizam a resistência de distintas organizações coletivas, pois, como ressalta a CNTE (2018), compete aos sindicatos de trabalhadores em educação e à sociedade civil organizada promover amplo debate a fim de arregimentar apoios que conduzam à revogação dos efeitos da contrarreforma. Dos atores sociais coletivos, o presente estudo toma como objeto o posicionamento político da Anfope e da CNTE em relação à atual reforma educacional e à BNCC. É resultado da pesquisa documental, que tomou por base os documentos e assinaturas conjuntas produzidos pelas referidas organizações sobre a temática em tela, entre 2016 e 2018. Fundamenta-se, epistemologicamente, no materialismo histórico-dialético, de Marx (1988), que compreende a história um processo dialético e a sociedade uma totalidade de relações entre humanos que se dá sempre no quadro histórico, particular, de um dado estágio de desenvolvimento social. Nesse sentido, a partir da análise documental, buscamos identificar o movimento de constituição da contrarreforma do Ensino Médio, suas contradições e resistências.

A escolha da Anfope e da CNTE como objetos de estudo baseou-se nas suas atuações, desde a origem, no final da década de 1970, na defesa da educação pública, gratuita, laica e de qualidade socialmente referenciada, conjugada a proposição de políticas públicas de formação de professores e de valorização do magistério. A centralidade da análise em organizações nacionais tem o objetivo de ressaltar a importância dos movimentos sociais e organizações coletivas como forma de enfrentamento no atual contexto de ataque a democracia e aos direitos garantidos.

À luz dessas considerações, o presente texto se estrutura em três tópicos. No primeiro, reflete as ações tomadas pelos dirigentes do Partido dos Trabalhadores (PT) e os governos de Lula da Silva e de Dilma Roussef que deram margens ao golpe de 2016. No segundo, discorre sobre alguns aspectos da nova organização curricular e a sua relação com as demais reformas em curso. Por fim, analisa os aspectos da contrarreforma do Ensino Médio criticados pelos intelectuais orgânicos individuais e coletivos, com destaque a Anfope e a CNTE.

\section{A PREPARAÇÃO DO TERRENO}

A ameaça a democracia e ao Estado Brasileiro de Direito vem se configurando gradadativamente desde 2014, quando os resultados das eleições para governo federal consagraram a vitória do projeto político e societário iniciado em 2003. A vitória do Partido dos Trabalhadores (PT) em três eleições consecutivas ao governo federal não significa que críticas não tenham sido dirigidas ao partido e aos governos de Lula da Silva e Dilma Roussef, inclusive por filiados e antigos aliados que direcionaram suas críticas ao afastamento ideológico de muitos dos princípios que o PT historicamente defendia.

Decerto, acontecimentos internacionais relacionados ao colapso dos regimes do leste europeu, simbolizado pela queda do muro de Berlim em 1989, e a derrota eleitoral de Lula da Silva nesse mesmo ano abriram caminho para a virada programática do partido. Como ressalta Mattos (2009), na campanha de 2002 já havia sido abandonado o chamado Programa Democrático-Popular que orientou a ação petista entre o fim dos anos 1980 e a campanha presidencial de Lula em 1998. Por um lado, a aposta na institucionalidade como estratégia de governabilidade e os altos índices internos e externos 
de aprovação do governo Lula promoveram uma margem de negociação com o Poder Legislativo e com organizações e movimentos sociais de distintas matrizes ideológicas; mas por outro, fez com que os dirigentes do PT conferissem pouca atenção à formação política da base partidária e à formação de novos quadros e lideranças políticas. Sob a bandeira de "governar para todos" e visando a permanência no poder optou por adotar a política do "presidencialismo de coalizão", constituída na aliança com partidos de distintas posições ideológicas e que impossibilitou o rompimento com a política de favorecimento ao grande capital, a reforma política e o combate às práticas de corrupção historicamente instituídas.

Um dos aspectos expostos pelo golpe parlamentar, jurídico e midiático foi a impossibilidade de a política de coalizão mascarar as contradições entre capital e trabalho e as disputas de seus respectivos projetos políticos e societários, além de explicitar o incômodo das classes dominantes e dirigentes brasileiras, de origem escravocrata e colonizadora, com a socialdemocracia "a moda PT", que possibilitou, apesar de pequenos, significativos avanços e conquistas dos movimentos sociais, sindicatos e partidos vinculados às lutas dos trabalhadores.

No aspecto educacional a ampliação de direitos se expressou, entre outras ações, na democratização de acesso ao Ensino Superior, na possibilidade de implementação do Ensino Médio Integrado com a criação dos Institutos Federais (IFs) e na ampliação de oportunidades para a conclusão da educação básica e para a qualificação profissional de jovens e adultos por meio de programas como o Proeja e o Projovem. Nos aspectos econômico e social destacam-se as políticas de transferência de renda para os setores mais pobres, como o Programa Fome Zero e Bolsa Família, os programas de construção de moradias populares, a recuperação expressiva do poder de compra do salário mínimo, a popularização do crédito para os segmentos até então excluído dessa possibilidade, a dinamização do mercado interno de consumo de massa, a reestruturação de carreiras e salários de servidores públicos e os programas de infraestrutura (BARBOSA; SOUZA, 2010).

Porém, a aceleração do desenvolvimento social ocasionado pela reorientação da política econômica para o modelo "novo desenvolvimentista", a partir de 2005, não representou ameaça a hegemonia do capital financeiro e nem para as parcerias público-privadas estabelecidas com os grandes grupos econômicos nacionais, iniciadas no governo Fernando Henrique Cardoso. Pelo contrário, esta política foi ampliada nos governos do PT e os representantes dos setores financeiros, da indústria, do agronegócio e de commodities conquistaram posições no primeiro escalão do governo e no conteúdo das políticas. Todavia, a crise econômica mundial em 2013 tornou expostas as contradições do "presidencialismo de coalizão" e a fratura existente na base governamental. Recrudesce, a partir de então, uma virulenta campanha contra o PT nos principais aparelhos midiáticos e a mobilização da direita conservadora sob a bandeira do combate a corrupção. Descontextualizada da crise mundial, a crise econômica brasileira foi identificada pelos planejadores/executores do golpe como produto da má gestão de um Estado benevolente que gasta mais do que arrecada e assolado em corrupção. Buscando minimizar as perdas e retomar suas margens de lucros, a elite econômica e política defende a necessidade das reformas fiscais e estruturais, que se materializam, entre outras, na retomada da política de privatização, na campanha contra os serviços e servidores públicos e na redução dos investimentos às políticas sociais. Apresenta a reforma trabalhista e a flexibilização das 
relações de trabalho como condições indispensáveis para reduzir os altos índices de desemprego e induzir a retomada dos investimentos do setor privado no país. Afinal, conforme as palavras de Henrique Meireles, minstro da fazenda do governo Temer, "todos devem dar sua cota de sacrifício".

Transcorridos três anos, não é isso o que se verifica na realidade concreta, mas sim um contexto desolador às classes trabalhadoras - para quem foram repassados todos os ônus da crise. Dados da Pnad-Contínua apontam o crescimento da taxa de desemprego, de 10,90\%, no período em que a presidente Dilma Roussef foi afastada do poder, em 12 de maio de 2016, para 11,6\% no último trimestre do governo Temer, em 2018 (BRASIL, 2019). Índice que permaneceu em crescimento e registrou no primeiro trimestre do governo Bolsonaro o quantitativo de 13,4 milhões de pessoas desempregadas, o correspondente a $12,7 \%$ da população ativa no país. Corrobora para a configuração desse quadro desolador o ataque aos sindicatos, a carestia dos alimentos, o aumento da pobreza e a perda de direitos.

Cabe destacar nessa breve análise conjuntural, que no Brasil do pós-golpe a onda ultraconservadora se estendeu a dimensão cultural, coadunando cultura autoritária, conservadorismo e fundamentalismo religioso (FRIGOTTO; FERREIRA, 2019). No atual governo Bolsonaro essa cultura autoritária e ultraconservadora tem se materializado de distintas formas: na intolerância à diversidade de pensamento e à determinados grupos da população, principalmente gays, negros e nordestinos; no ataque a suposta ideologia de gênero e na criminalização dos movimentos sociais. Professores e teóricos da matriz histórico-crítica não têm passado incólumes nesse processo, acusados pelo discurso ultraconservador como doutrinadores do chamado "marxismo cultural". Sob a bandeira do moralismo que invoca o signo de "Deus, Pátria e Família", assim como ocorrera no golpe civil-militar de 1964, os ultraconservadores buscam silenciar professores e destituir o conhecimento escolar como instrumento de consciência crítica dos sujeitos com vista à transformação de si e de sua realidade histórica. Este é o propósito das campanhas contra o educador Paulo Freire, mundialmente referenciado.

Para um melhor entendimento do contexto de contrarreformas e de ultraconservadorismo a qual a contrarreforma do Ensino Médio é uma de suas expressões, não pode ser negligenciada a apreensão das classes dominantes e dirigentes à nova expressão política juvenil, caracterizada pelos movimentos de junho de 2013 e pa ocupação de escolas pelos estudantes secundaristas em várias cidades brasileiras em 2016. Na concepção de Motta e Frigotto (2017), a contrarreforma do Ensino Médio, em sua dimensão política, deve ser compreendida como estratégia de controle social, uma vez que as elites brasileiras jamais aceitaram as manifestações juvenis que confrontaram o poder instituído pela ampliação de direitos. O desmérito e ataque as Ciências Humanas explicita o temor que os herdeiros da "casa grande" nutrem em relação à educação crítica e emancipatória. E assim, um movimento articulado se engendra: retira a obrigatoriedade da oferta de Filosofia e Sociologia no novo currículo do Ensino Médio e reduz o investimento público para a formação nessas áreas sob a justificativa de que elas não geram retorno imediato ao contribuinte. Desse modo, resistir a Lei $n^{\circ}$ 13.415/2017 e a BNCC significa resistência ao projeto de sociedade que os executores e apoiadores do golpe visam implementar, do qual a educação tem muito a contribuir.

\section{A REFORMA DO ENSINO MÉDIO: UMA PONTE PARA O PASSADO}

Reflexão e Ação [ISSN 1982-9949]. Santa Cruz do Sul, v. 29, n. 1, p. 187-201, jan./abr. 2021. https://online.unisc.br/seer/index.php/reflex/index 
A contrarreforma do Ensino Médio tem despertado o interesse de pesquisadores de diferentes matrizes epistemológicas. Silva (2018) e Cunha (2017) têm desvelado seu caráter retrógrado e conservador, demonstrando que o "novo" desenho curricular atende a interesses antigos. Não por acaso, a Lei $n^{\circ}$ 13.415/2017 tenha incorporado quase tudo do PL no 6.840/2013, apesar das críticas recebidas. A modificação mais significativa foi a retirada da obrigatoriedade de Educação Física, Arte, Sociologia e Filosofia que passaram a ser definidas como "estudos e práticas".

De modo geral, a Lei estabelece que a carga horária do "novo" Ensino Médio deverá ser de 1.400 horas/ano, a ser implantada de forma gradual pelas redes de ensino. Nessa primeira fase da implementação a meta é que as redes ofereçam pelo menos 1000 horas/anual até o início do ano letivo de 2022. Contudo, a carga horária destinada a BNCC não poderá ultrapassar a 1800 horas, o que corresponde a menos 600 horas da carga horária do atual Ensino Médio propedêutico, que é de 2.400 horas, e será inferior a $50 \%$ depois que a carga horária total de 4.200 horas for implementada. Além disso, como salienta a CNTE (2018), a legislação abre possibilidade para que as redes decidam por dedicar menos carga horária a essa parte do currículo. Reduzir a carga horária da base comum curricular significa negar o que é o comum na educação básica, cerceando os jovens das classes populares ao acesso ao conhecimento sistematizado produzido historicamente pela humanidade, já que para muitos deles a escola se constitui no principal espaço de acesso a esse conhecimento.

A parte flexibilizada do currículo é constituída pelos chamados "itinerários formativos, não sendo as escolas obrigadas a oferecer todos eles, mas ao menos um, e caso não ofereça sua área de interesse, o estudante poderá cursá-la em outra unidade escolar. Tendo em vista que no Brasil há cerca de três mil municípios com uma única escola pública de Ensino Médio e tantos outros sem nenhuma instituição escolar, a possibilidade de escolha tão propagada nos discurso governamental e nas campanhas midiáticas possivelmente não acontecerá para milhares de jovens pobres, pois diante das limitações determinadas pela EC $n^{\circ}$ 95/2016, as redes de ensino desses municípios, muito provavelmente, não terão recursos suficientes para cobrir todos os gastos com deslocamento e alimentação dos estudantes para outros municípios, apesar da ajuda financeira advinda da União.

Ademais, a contrarreforma confere novo peso ao ensino técnico sob a justificativa de que a etapa final da educação básica não qualifica os jovens para o mercado de trabalho, visto que apenas 10\% das matrículas estão na Educação Profissional. Retorna-se, assim, o espírito da política educacional discriminadora instituída pela Lei $n^{0} 5692 / 71$, do período da ditadura civil-militar, assim como as proposições do Dec. 2208/97 e das Diretrizes Curriculares Nacionais do Ensino Médio (DCNEM) de 1998, de adequar a educação às mudanças do setor produtivo e preparar os jovens para a flexibilização das relações e do mercado de trabalho (FERRETI; SILVA, 2017). Nas proposições da DCNEM/1998 e da atual BNCC cabe a educação escolar desenvolver as competências exigidas pelo atual modelo de acumulação flexível. Nessa mesma direção, a possibilidade de contratar profissionais com "notório saber" para a oferta da formação profissional é outra problematização feita por professores, especialistas e suas organizações representativas, revelando ser a especialização técnica e a aquisição de competências para a empregabilidade as preocupações principais da formação e não a formação integral do jovem brasileiro, conforme indica a BNCC. Acrescenta-se, outrossim, que a 
contratação de professores por "notório saber" possibilitará o enxugamento do quadro do magistério nas redes públicas, visto que o poder público, à luz da reforma trabalhista (Lei n 13.467/2017), poderá vir a priorizar ainda mais contratos precarizados e/ou terceirizados conforme sinaliza a CNTE (2018).

Perante o exposto, a reforma proposta não ataca o problema da qualidade social do Ensino Médio. O enxugamento dos conteúdos justificado pelo excesso de disciplinas visa, na realidade, reduzir a formação crítica das novas gerações, conformando-as para as vigentes relações precarizadas de trabalho, como apontam os estudos da área de trabalho e educação, como Lima e Maciel (2018), Ferreti (2018) e Kuenzer (2017), entre outros. Essa intenção se explicita no discurso do integrante do "Movimento Todos pela Educação" em uma das audiências públicas que debateu a Medida Provisória:

No Brasil há uma demanda latente por um currículo mais prático, com matérias mais voltadas para a vida profissional, como economia, administração e relações financeiras, como se portar em uma entrevista, noções de ética e informações a respeito de informática e testes vocacionais (apud FERRETI; SILVA, 2017, p. 395).

Contrários aos objetivos explícitos/implícitos da contrarreforma, diversos atores têm se mobilizado e resistido, seja individualmente e/ou por meio suas organizações coletivas.

\section{REFORMA DO ENSINO MÉDIO: O QUE PENSAM A ANFOPE E A CNTE?}

Desde a edição da Medida Provisória a Anfope e a CNTE vêm se manifestando contrárias ao caráter impositivo do processo de elaboração, discussão e aprovação da BNCC da Educação Infantil, Ensino Fundamental e Médio, ressaltando tratar-se de uma centralização curricular dissociada das demandas formativas e das realidades locais. No documento produzido para a audiência pública da região Centro-Oeste, ocorrida em 2018, a Anfope ressalta que a complexidade e a diversidade brasileira não permitem a adoção de uma política curricular nacional de matrizes curriculares homogeneizadas, que venham ameaçar o princípio federativo republicano da autonomia dos sistemas estaduais e municipais de ensino e a construção dos projetos político-pedagógicos das instituições escolares, conforme explicitado nas Diretrizes Curriculares Nacionais da Educação Básica, nas Diretrizes Curriculares para o Ensino Médio e nas Diretrizes Curriculares Nacionais de Formação Inicial e Continuada de Profissionais do Magistério. Nessa perspectiva, identifica a BNCC como

\footnotetext{
uma proposição curricular anacrônica e ultrapassada que recupera a concepção de competências e habilidades, que aponta para a implantação de processos de centralização, padronização e controle incompatíveis a formação integral de estudantes e professores, desrespeitando a rica diversidade cultural e autonomia das escolas brasileiras (ANFOPE, 2018,
} p.1).

As referidas organizações ressaltam que a homogeneização visa a vincular os processos educativos às avaliações em larga escala, favorecendo uma aprendizagem tácita em prol do mercado de trabalho. Esta é a razão de os planejadores/executores da contrarreforma justificarem o baixo rendimento dos alunos nas avaliações nacionais e internacionais, associando-o ao desinteresse dos 
estudantes ocasionado por um currículo extenso e nada flexível. Não estabelecem nenhuma relação ao pouco investimento na formação docente (inicial e continuada), a precária infraestrutura e as condições de trabalho vivenciadas na maioria das escolas públicas, muitas das quais sem laboratórios de ciências, laboratórios de informática, quadras de esportes decentes, bibliotecas e merenda dignas. Como bem destaca Marta Vanelli, diretora da CNTE, em uma das audiências públicas que debateu a MP 746/2016,

não é possível pensar em como melhorar o ensino médio só pensando na mudança curricular. [...] Nós precisamos pensar aqui em como nós vamos melhorar a infraestrutura das escolas [...] em como nós vamos valorizar os profissionais da educação. O que está colocado para nós nessa medida provisória é desresponsabilizar o Estado. [...] Aqui, a flexibilização é no sentido da privatização (apud FERRETI; SILVA, 2017, p. 396).

O interesse do empresariado nacional com a contrarreforma do Ensino Médio não consiste apenas em formar os trabalhadores requeridos pelo atual regime de acumulação flexível. Como têm reafirmado a Anfope e a CNTE, há também o interesse nas parcerias público-privadas, apresentadas pelo governo e seus apoiadores como meio de contornar a ausência de infraestrutura satisfatória para a realização da formação técnica e profissional. Que poderão ser custeadas com recursos do FUNDEB, inclusive para a contratação de empresas e fundações privadas que atuam na modalidade da educação à distância tanto para a "venda de material didático e a oferta de serviços de consultoria para a implementação da BNCC, [quanto para] a venda de pacotes de formação continuada" (ANFOPE, 2018, p.2).

Sem contar que a educação minimalista e pragmática proposta para as camadas populares não proporcionará as ferramentas conceituais e intelectuais necessárias para aprovação nos exames de ingresso para as universidades públicas, o que incidirá no incremento das matrículas da rede privada, cumprindo a Lei no 13.415/2017 os objetivos de contenção das camadas populares ao Ensino Superior público, orientando-se pelos mesmos propósitos da Lei 5.692/71 instituída no governo civilmilitar (CUNHA, 2017). Portanto, a reforma "caminha na direção oposta das recentes políticas de inclusão escolar e universitária, pois aponta para a maior parte da população o Ensino Médio como etapa de conclusão dos estudos - independente da vontade dos estudantes" (CNTE, 2018, p.23). A reforma do Ensino Médio se constitui em um dos braços do projeto de desestruturação e sucateamento do Ensino Superior público, cujo horizonte é a privatização.

Desse modo, a aprovação do CNE em permitir que até $20 \%$ da carga horária do Ensino Médio possa ser ofertada na modalidade à distância, podendo chegar a $40 \%$ no caso do ensino noturno, atende a múltiplos interesses: aumento das margens de lucro do empresariado do setor educacional; reduzir os investimentos públicos com a educação básica e superior; contornar as dificuldades de cumprimento da carga horária anual do ensino noturno, visto que dificilmente o tempo destinado às aulas nesse turno poderá ser de cinco horas.

Outrossim, a Anfope e CNTE denunciam o simulacro que as audiências públicas se constituíram, uma vez que o CNE "desconsiderou as críticas propositivas das entidades educacionais e privilegiou fortemente setores do empresariado interessados na padronização do ensino para atender fins mercadológicos" (ANFOPE, 2017, p.2). Enfatizam que a redução do currículo - ao mínimo - retira dos 
jovens da escola pública o direito à formação plena e de qualidade, além de consolidar o processo de apartheid socioeducacional dos mais pobres. Ao privilegiar o desenvolvimento de competências e priorizar os conhecimentos de Língua Portuguesa e Matemática, a BNCC nega o direito aos conhecimentos de outros campos científicos que deveriam ser comuns a todos.

Outro ponto destacado pelas organizações é que a BNCC distorce o conceito de educação integral. "A proposta de tempo integral apresentada, reduzida a um simples aumento da carga horária de determinadas disciplinas, não contempla a concepção de educação integral" (ANFOPE, 2016, p.2). O documento da Base destaca que a educação integral deve visar o desenvolvimento humano global, o que "implica compreender a complexidade e a não linearidade desse desenvolvimento, rompendo com visões reducionistas que privilegiam ou a dimensão intelectual (cognitiva) ou a dimensão afetiva" (BRASL, 2017, p.14). Significa desenvolver as múltiplas competências (organizativas, comportamentais, comunicativas e socioemocionais) com vista a preparar as crianças, adolescentes, jovens e adultos a enfrentarem os desafios da sociedade contemporânea, entre as quais destacam:

\begin{abstract}
reconhecer-se em seu contexto histórico e cultural, comunicar-se, ser criativo, analítico-crítico, participativo, aberto ao novo, colaborativo, resiliente, produtivo e responsável requer muito mais do que o acúmulo de informações. Requer o desenvolvimento de competências para aprender a aprender, saber lidar com a informação cada vez mais disponível, atuar com discernimento e responsabilidade nos contextos das culturas digitais, aplicar conhecimentos para resolver problemas, ter autonomia para tomar decisões, ser proativo para identificar os dados de uma situação e buscar soluções, conviver e aprender com as diferenças e as diversidades (BRASIL, 2017, p. 14).
\end{abstract}

Gawryszewski (2017) destaca que o desenvolvimento das competências socioemocionais instado na BNCC aponta para a formação de um trabalhador resiliente, suscetível a suportar incertezas e assimilar mudanças abruptas que poderão ser constantes em sua vida, sobretudo em um contexto de aplicação de contrarreformas que implicam na retirada/diminuição de direitos. Dessa forma, apesar de utilizar os conceitos de igualdade, diversidade e equidade na tentativa de legitimar seu conteúdo, tratase de uma concepção de educação integral distinta da concepção defendida pelos teóricos da matriz histórico-crítica, por assentar-se na dicotomia entre formação geral e formação profissional e não se pautar na integração curricular em torno dos eixos da ciência, da cultura, do trabalho e da tecnologia a fim de promover nos jovens a compreensão crítica do trabalho e da sociedade levando-os a uma ação política com vista à desalienação e a transformação social (BARBOSA, 2018).

No conjunto das contrarreformas instituídas no Brasil pós-golpe, a Lei $n^{\circ}$ 13.415/2017 intensificará processos de precarização do ensino nas escolas públicas, prejudicando principalmente os estudantes oriundos das camadas populares, já que as mudanças propostas dificilmente acontecerão nas escolas reservadas às elites brasileiras, do mesmo modo que não cumpriram com a compulsoriedade do ensino técnico determinada pela da Lei $n^{\circ}$ 5692/71. E como ressaltam a Anfope e a CNTE, os professores também sofrerão com casos de demissões, precarização da profissão e o reducionismo da formação docente atrelada às imposições da BNCC.

\title{
CONSIDERAÇÕES FINAIS
}

Reflexão e Ação [ISSN 1982-9949]. Santa Cruz do Sul, v. 29, n. 1, p. 187-201, jan./abr. 2021.

https://online.unisc.br/seer/index.php/reflex/index 
Conforme foi exposto ao longo desse texto, diversos aspectos da Lei $n^{\circ} 13.415 / 2017$ têm mobilizado a resistência individual e/ou coletiva de estudantes e profissionais da educação por entenderem que as mudanças propostas incidirão no rebaixamento da qualidade social da educação ofertada as camadas populares, aliada a exclusão escolar de muitos jovens.

De acordo com a Portaria 1145/2016, a implantação pelas redes públicas das mudanças propostas dar-se-á por meio da adesão das escolas ao chamado Programa de Fomento à Implementação das Escolas em Tempo Integral. Considerando que o agravamento das condições econômicas e o crescimento da pobreza dos últimos anos têm levado os jovens das classes menos abastadas a se inserirem cada vez mais precocemente no mercado de trabalho (formal ou informal), possivelmente não terão meios para se dedicarem aos estudos em tempo integral caso não haja uma política que estimule sua permanência na escola. Acrescenta-se a infraestrutura insatisfatória da maioria das escolas do país, pois como ressalta a CNTE (2018, p. 36) "a implementação de uma escola de tempo integral não pode prosperar sem a devida estrutura física, de recursos humanos, de materiais didático-pedagógicos e de projeto curricular que atendam aos anseios da comunidade e que possibilitem a máxima inclusão dos estudantes". A escola não será inovadora apenas pelo nome; é preciso garantir as condições para torná-la atraente, prazerosa e útil à vida dos jovens. Caso contrário, como demonstram as experiências das Escolas de Referência em Ensino Médio de Pernambuco (EREMs), implantadas a partir de 2008 no âmbito do Programa de Educação Integral (SILVA; SILVA, 2014), a extensão da jornada escolar sem infraestrutura necessária pode agravar a evasão escolar em vez de inibi-la. E tendo em vista o atual contexto de redução dos investimentos com as políticas sociais, é preciso questionar, em diálogo com Cavaliere (2009), a concepção de escola de tempo integral que tem mobilizado os planejadores da reforma. Trata-se de uma concepção de escola ou da ocupação de alunos carentes em tempo integral para evitar sua marginalidade?

Por fim, cabe ressaltar que a educação reducionista proposta pela BNCC se distancia da formação integral e humana defendida pelos teóricos da matriz histórico-crítica, bem como das finalidades do Ensino Médio expressas na vigente LDB, que são, entre outras, preparar o educando para o trabalho e para a cidadania; desenvolver a autonomia intelectual e o pensamento crítico, assim como a compreensão dos fundamentos científico-tecnológicos dos processos produtivos, relacionando a teoria com a prática, no ensino de cada disciplina (BRASIL, 1996). Ao contrário, por estar atrelada aos interesses do mercado e com a nova fase do capitalismo, conforme as orientações do Banco Mundial (2011) e da Unesco (2008), o "novo" Ensino Médio compromete a formação que oportuniza a maturidade intelectual e emancipação dos sujeitos; formação esta, defendida pelas organizações aqui retratadas e por todos os profissionais da educação que lutam por uma educação pública de qualidade para todos os cidadãos e cidadãs brasileiras.

\section{REFERÊNCIAS}


1. ASSOCIAÇÃO NACIONAL PELA FORMAÇÃO DOS PROFISSIONAIS DA EDUCAÇÃO ANFOPE. Manifesto Contra a Medida Provisória n. 746/2016, 12 out. 2016. Disponível: <http://www.anfope.org.br/wp-content/uploads/2018/05/Manifesto-Anfope-MP-74612.10.2016R.pdf. Acesso em: 27 mar. 2019.

2. ASSOCIAÇÃO NACIONAL PELA FORMAÇÃO DOS PROFISSIONAIS DA EDUCAÇÃO ANFOPE. Posição da ANFOPE sobre a BNCC, 11 set. 2017. Disponível: <http://www.anfope.org.br/wp-content/uploads/2018/05/CARTA-de-Brasilia_ANFOPE-V-AudienciaPublica-CNE.-11.9.2017.pdf>. Acesso em: 25 mar.2019.

3. ASSOCIAÇÃO NACIONAL PELA FORMAÇÃO DOS PROFISSIONAIS DA EDUCAÇÃO ANFOPE. Documento apresentado na audiência pública da região Centro-Oeste sobre a BNCC do ensino médio no Conselho Nacional de Educação, 14 set. 2018. Disponível: $<$ http://www.anfope.org.br/wp-content/uploads/2018/11/Nota-Anfope-BNCC-EM-2018-Brasilia14setembro.pdf>. Acesso em: 25 mar. 2019.

4. ASSOCIAÇÃO NACIONAL PELA FORMAÇÃO DOS PROFISSIONAIS DA EDUCAÇÃO - ANFOPE et all. O Desmonte da Escola Pública e os Efeitos da Reforma do Ensino Médio: exclusão, precarização, privatização, desresponsabilização do Estado, mar. 2018. Disponível: <http://www.anfope.org.br/wp-content/uploads/2018/11/Manifesto_entidades-Ensino-Medio20mar\%C3\%A702018.pdf>. Acesso em: 20 mar. 2019.

5. BANCO MUNDIAL. Aprendizagem para Todos: Investir nos Conhecimentos e Competências das Pessoas para Promover o Desenvolvimento. Estratégia 2020 para a Educação. Grupo Banco Mundial, 2011.

6. BARBOSA, Carlos Soares. Trabalho e educação no pensamento (neo)liberal e histórico-crítico: fundamentos para pensar a reforma curricular no ensino médio. Tear: Revista de Educação Ciência e Tecnologia, Canoas, v.7, n.1, 2018. ISSN 2238-8079. Disponível: <https://periodicos.ifrs.edu.br/index.php/tear/article/view/2527>. Acesso em: 15 jan. 2018.

7. BARBOSA, N.; SOUZA, J. A. P. A inflexão do governo Lula: política econômica, crescimento e distribuição de renda. In: SADER, Emir.; GARCIA, Marco Aurélio. (Orgs). Brasil entre o passado e o futuro. São Paulo: Fundação Perseu Abramo: Boitempo, 2010.

8. BRASIL. Base Nacional Comum Curricular - Ensino Médio. Ministério da Educação. Documento homologado pela portaria no 1570, Diário Oficial da União, Brasília-DF, Seção 1, p.146, de 21 de dezembro de 2017. 

Educação Nacional. Diário Oficial da União, Brasília-DF, 23 dez. 1996.

11. BRASIL. Lei n 13.005, de 25 de junho de 2014. Aprova o Plano Nacional de Educação - PNE e dá outras providências. Diário Oficial da União, Brasília, 26 de junho de 2014. Disponível em: <http://www.planalto.gov.br/ccivil_03/_ato2011-2014/2014/lei//13005.htm>. Acesso em: 23 mar. 2017. de 1996, que estabelece as diretrizes e bases da educação nacional, e 11.494, de 20 de junho 2007, que regulamenta o Fundo de Manutenção e Desenvolvimento da Educação Básica e de Valorização dos Profissionais da Educação, e institui a Política de Fomento à Implementação de Escolas de Ensino Médio em Tempo Integral. Disponível em: <http://www.planalto.gov.br/ccivil_03/_Ato2015-2018/2017/Lei/L13415.htm>. Acesso em: 22 jun. 2017.

BRASIL. Medida Provisória 746, de 23 de setembro de 2016. Diário Oficial da República Federativa do Brasil, Poder Executivo, Brasília-DF, p.1. Disponível em: <http://www.planalto.gov.br/ccivil_03/_ato2015-2018/2016/Mpv/mpv746.htm>. Acesso em: 18 fev. 2018.

14. BRASIL. Pesquisa Nacional por Amostra de Domicílios Contínua - PNAD Contínua. IBGE: Instituto Brasileiro de Geografia e Estatística. PNAD Contínua, 2019. Disponível em: $<$ https://agenciadenoticias.ibge.gov.br/agencia-sala-de-imprensa/2013-agencia denoticias/releases/24284-pnad-continua-taxa-de-desocupacao-e-de-12-7-e-taxa-de-subutilizacaoe-de-25-0-no-trimestre-encerrado-em-marco-de-2019>. Acesso em: 22 mai. 2019.

CAVALIERE, Ana Maria V. Escolas de Tempo Integral versus Alunos em Tempo Integral. Em Aberto, Brasília, v. 22, n. 80, p. 51-64, abr. 2009. ISSN 2176-6673. Disponível: < http://emaberto.inep.gov.br/index.php/emaberto/article/view/2220/2187>. Acesso em: 15 set. 2015. DOI: http://dx.doi.org/10.24109/2176-6673.emaberto.31i103

CONFEDERAÇÃO NACIONAL DOS TRABALHADORES EM EDUCAÇÃO - CNTE. Cadernos de Educação, Brasília/DF, ano XXII, n. 30, p. 1-120, jan./jun. 2018. ISSN 1982-758X. Disponível em: <http://sinte-sc.org.br/files/1081/cadernos_de_educacao_n.30_2018_miolo_ensino_medio.pdf>. Acesso em: 20 dez.2018.

17. CUNHA, Luiz Antônio. Ensino Médio: atalho para o passado. Educação \& Sociedade, Campinas, v.38, n.139, p.373-384, abr./jun., 2017. ISSN 0101-7330. Disponível: 
<http://www.scielo.br/pdf/es/v38n139/1678-4626-es-38-139-00373.pdf>. Acesso em: 05 nov. 2017. Doi: http://dx.doi.org/10.1590/es0101-73302017176604.

18. FERRETTI, Celso João. A reforma do ensino médio: desafios à educação profissional. Holos, ano 34, v. 04, p.261-271, 2018. ISSN 1807-1600. Disponível em: < http://www2.ifrn.edu.br/ojs/index.php/HOLOS/article/view/6975/pdf>Acesso em: 15 set. 2019. Doi: 10.15628/holos.2018.6975.

19. FERRETTI, Celso João; SILVA. Mônica Ribeiro. Reforma do ensino médio no contexto da medida provisória n 746/2016: estado, currículo e disputas por hegemonia. Educação \& Sociedade, Campinas, v.38, ${ }^{\circ}{ }^{\circ} 139$, p. 385-404, abr./jun., 2017, p. 385-404. ISSN 0101-7330. Disponível: http://www.scielo.br/pdf/es/v38n139/1678-4626-es-38-139-00385.pdf. Acesso em: 18 mai. 2018. Doi: http://dx.doi.org/10.1590/es0101-73302017176607.

20. FRIGOTTO, Gaudêncio; FERREIRA, Sônia. Maria. Cultura autoritária, ultraconservadorismo, fundamentalismo religioso e o controle da educação básica pública. Trabalho Necessário, v.17, n.32, jan/abr, 2019 ISSN 1808-799X. Disponível: <http://periodicos.uff.br/trabalhonecessario/article/viewFile/28304/16435>. Acesso em: 03 mai. 2019.

21. GAWRYSZEWSKI, Bruno. Tempo integral: mais uma solução para o ensino médio? Revista HISTEDBR On-line, Campinas, v.18, n.3 [77], p.826-843, jul/set. 2018. ISSN: 1676-2584. Doi: https://doi.org/10.20396/rho.v18i3.8651796

22. KRAWCZKY, Nora. Uma roda de conversa sobre os desafios do ensino médio. In: DAYRELL, J.; CARRANO, P.; MAIA, C. L. Juventude e Ensino Médio: sujeitos e currículos em diálogo. Belo Horizonte: Editora UFMG, 2014.

23. KUENZER, Acácia Z. Trabalho e escola: a flexibilização do ensino médio no contexto do regime de acumulação flexível. Educação e Sociedade, Campinas, v.38, n ${ }^{\circ}$ 139, p. 385-404, abr-jun, 2017, p. 331-354.

LIMA, Marcelo; MACIEL, Samanta Lopes. A reforma do Ensino Médio do governo Temer: corrosão do direito à educação no contexto de crise do capital no Brasil. Revista Brasileira de Educação [online], v. 23, 2018. ISSN 1809-449X. Disponível em: <https://www.scielo.br/pdf/rbedu/v23/1809449X-rbedu-23-e230058.pdf > Acesso em: 07 nov. 2019. Doi: http://dx.doi.org/10.1590/s141324782018230058.

MARX, Karl. O Capital: crítica da economia política. $3^{\text {a }}$ edição, São Paulo: Nova Cultural, 1988. 
26. MOTTA, Vânia C.; FRIGOTTO, Gaudêncio. Por que a urgência da reforma do ensino médio? Medida provisória n 746/2016 (Lei n 13.417/2017). Educação e Sociedade, Campinas, v.38, n. 139, p. 355-372, abr-jun, 2017. ISSN 1678-4626. Disponível em: < https://www.scielo.br/pdf/es/v38n139/1678-4626-es-38-139-00355.pdf> Acesso em: 08 set. 2017. Doi: 10.1590/es0101-73302017176606.

27. SILVA, Katharine N. P.; SILVA, Jamerson A. de A. da. Accountability e intensificação do trabalho docente no Ensino Médio Integral de Pernambuco. Práxis Educativa, Ponta Grossa, v. 9, n. 1, p. 117-140, jan.-jun. 2014. elSSN: 1809-4309. Disponível em: http://www.revistas2.uepg.br/index.php/praxiseducativa Acesso em: 10. mar. 2016. Doi: 10.5212/PraxEduc.v.9i1.0006.

28. UNESCO. Reforma da Educação Secundária: rumo à convergência entre a aquisição de conhecimento e o desenvolvimento de habilidade. Brasília: Unesco, 2008. Disponível em: https://unesdoc.unesco.org/ark:/48223/pf0000142463_por Acesso em: 25/10/2014.

\section{Carlos Soares Barbosa}

Doutor em Políticas Públicas e Formação Humana (UERJ). Professor Adjunto da Faculdade de Educação, da Universidade do Estado do Rio de Janeiro (UERJ), Campus Maracanã, e do Programa de Pós-Graduação em Educação: processos formativos e desigualdades sociais.

\section{Como citar este documento:}

BARBOSA, Carlos Soares. ORGANIZAÇÕES DOCENTES NA REFORMA DO ENSINO MÉDIO: ANÁLISE DO POSICIONAMENTO DA ANFOPE E DA CNTE. Reflexão e Ação, Santa Cruz do Sul, v. 29, n. 1, p. 187-201, jan. 2021. ISSN 1982-9949. Acesso em: doi: http://dx.doi.org/10.17058/rea.v29i1.13616 